\title{
The Latvian Social Science Data Archive
}

The first Internet connection in Latvia was created in 1991 during the so-called "putsch" when the connection via satellite from the University of Latvia to Sweden was the only mean of communication with the outside world. Since then the Internet has been developing in Latvia. Still there is a shortage of public financing and IT specialists that hinders further progress in this area. In 1999 "The National Program of Information" and in 2000 a social and economic program "e-Latvia" were approved. The aim of those and several other specific programs is to promote the establishment of the national information structure.

The number of Internet users in Latvia at the end of 2000 was approximately 150 thousand, i.e. $10 \%$ of working age population. Internet access is available in $14 \%$ of schools and only $5 \%$ of public and research libraries. There is also a great lack of computers and still more money is spent on buying hardware than on purchasing software. At the same time the number of Internet users was $50 \%$ more that at the beginning of 1999 and the number is increasing rapidly (Economic Development of Latvia. Report. Ministry of Economy, Republic of Latvia, Riga, December, 2000, p.92 - 93). Still we are far from reaching the standards of the leading countries where $60 \%$ of population are IT users.

All the above mentioned problems affect the development of the electronic archiving and exchanging of data in Latvia. The establishment of an electronic on-line archive reflects a general trend to move away from paper-based information exchange among the researchers who specialize in social sciences and humanities. Compared to traditional archives, the development of electronic data bases and other electronic services do not develop dynamically in Latvia. There are several reasons for it:

1. The results of many social studies in Latvia are preserved only partly, but due to the insufficient documentation the use of them is very limited.

2. Even sufficiently documented data are accessible only to specialists, as the use of them requires expensive software.

3. The opportunities of scientists to inform the society on the results of their research and the opportunities of the society to obtain the necessary social information are limited.

The Latvian Social Science Data Archive (LSZDA) is currently being developed with the financial support of the Latvian Science Council (the program 'Social Development and Social Security’, grant No. 93.330) and the SOROS Foundation - Latvia (Transformation of Education Program). Compared to other data archives, the technical aspects of the LSZDA are, for financial reasons, rather limited.

The LSZDA is supposed to serve the following purposes:

1. to gather and maintain social science data that characterize Latvia and the Latvian social scientists;

2. to facilitate the development of the Latvian social sciences and to open access to research results, facilitating the dissemination of data and documentation;

3. to make data available for secondary analysis, to improve the quality of research and the credibility of results;

4. In the area of educational aspects, to serve as an information base for training in the social sciences as well as to provide the analysis opportunities of the sociological data to a broader range of users.

These activities will facilitate the more efficient disposition of resources that are granted for research purposes. The archive also tries to provide Latvian scientists and other interested parties with access to data archives in other countries, as well as provide foreign researchers with opportunities to learn more about Latvia and its social sciences. At the present moment a number of articles (mostly in English) is available. The publications of the Latvian social scientists who worked outside Latvia during the Soviet occupation are represented very widely in the bibliographic file which has more than 1,000 entries covering the time period from the beginning of the 20th century to the 1980ies. There are no limitations for access and all information is available free of charge. 
Until 1999 the data collections were accessible only to authorised people who used SPSS software. One of the urgent tasks of the archive was to create a data analyses possibility for a broader range of the people concerned and especially for the students of sociology and other social sciences. In 1999 the data documentation system of the Swedish Social Science Data Service (Gothenburg) was mastered, which allows the analysis of the data collections to those users who have no access to the SPSS software. These data collections can be processed on-line or by maintaining them on a CD-ROM for the users without any background knowledge. In 1999 the data from three modules of the International Social Survey Programme (ISSP) were documented (National Identity, Role of Government, Religion), and an agreement has been achieved on the possibility to use this system for the documentation of further studies.

Contact: Ausma Tabuna, LSZDA, Akademijas laukums 1, Riga, LV-1940, Latvia. Phone: +371 7227110, Fax: +371 7210806. Internet: http://www.lszda.lv. E-mail: ausmat@1za.lv 